\title{
Composição Química, Digestibilidade dos Nutrientes e da Energia de Diferentes Milhetos (Pennisetum glaucum (L.) R. Brown) em Suínos ${ }^{1}$
}

\author{
Alexandre Orio Bastos ${ }^{2}$, Ivan Moreira ${ }^{*}$, Antonio Cláudio Furlan ${ }^{3}$, Alessandro Luis Fraga ${ }^{4}$, \\ Ricardo Pinto de Oliveira ${ }^{4}$, Elir de Oliveira ${ }^{5}$
}

\begin{abstract}
RESUMO - Foram conduzidos dois ensaios de digestibilidade, objetivando-se estudar o valor nutricional de quatro diferentes milhetos (BN2, COMUM, IAPAR e IAPAR-REPASSE) processados em moinhos com três tipos de peneiras (diâmetros de furo de 3, 2 e 1 mm). Os coeficientes de digestibilidade (CD) da energia bruta (CDEB) e o coeficiente de metabolizabilidade (CM) da energia bruta (CMEB) relativos à peneira de 3 mm foram: 63,09 e 61,20\% (COMUM); 71,57 e 69,66\% (IAPAR) e 67,39 e 65,60\% (BN2). Os CD e CM da energia do COMUM foram inferiores ao IAPAR e ambos foram semelhantes ao BN2. O IAPAR-REPASSE apresentou CDEB de 70,62\% e CMEB de 68,49\%, semelhante ao IAPAR. O IAPAR-1 mm apresentou maior CDEB e CMEB (84,61 e 81,41\%) que o IAPAR-3 mm (70,59 e $68,71 \%$ ) e o IAPAR-2 mm (77,73 e 75,46\%). Os valores de energia digestível (ED) e energia metabolizável (EM) para o IAPAR (3 mm) foram de $3.030 \mathrm{kcal} / \mathrm{kg}$ e $3.001 \mathrm{kcal} / \mathrm{kg}$, respectivamente. Verificou-se ED de 3.083 e $3.355 \mathrm{kcal} / \mathrm{kg}$ e EM de 2.993 e $3.228 \mathrm{kcal} / \mathrm{kg}$ para o IAPAR (2 e $1 \mathrm{~mm}$ ). O IAPAR-REPASSE apresentou valores de $2.849 \mathrm{kcal} / \mathrm{kg}$ (ED) e $2.763 \mathrm{kcal} / \mathrm{kg}$ (EM), enquanto o COMUM (3 e $2 \mathrm{~mm}$ ), de 2.574 e $3.022 \mathrm{kcal} / \mathrm{kg}$ (ED) e 2.497 e $2.932 \mathrm{kcal} / \mathrm{kg}$ (EM), e o BN2 (3 e $2 \mathrm{~mm}$ ), de 2.692 e $3.047 \mathrm{kcal} / \mathrm{kg}$ (ED) e 2.620 e 2.966 $\mathrm{kcal} / \mathrm{kg}(\mathrm{EM})$. As diferentes variedades de milheto apresentaram variações em sua composição química que resultaram em diferenças no valor nutricional, sendo o milheto IAPAR o que apresentou melhor valor, seguido pelo BN2 e o COMUM.
\end{abstract}

Palavras-chave: alimento alternativo, granulometria, nutrientes digestíveis

\section{Chemical Composition, Nutrients and Energy Digestibility of Pearl Millets (Pennisetum glaucum (1.) R. Brown) Fed to Growing Pigs}

\begin{abstract}
Two digestibility trials were carried out, to study the nutritional value of four types of pearl millet (BN2, Comum, Iapar and Iapar-Repasse), grounded through 3, 2, and $1 \mathrm{~mm}$ screen. The digestibility coefficient (DC) of gross energy (GEDC) and gross energy metabolization coefficient (GEMC) relative to $3 \mathrm{~mm}$ screen were: 63.09 and $61.20 \%$ (Comum); 71.57 and $69.66 \%$ (Iapar) and 67.39 and $65.60 \%$ (BN2). The GEDC and GEMC of COMUM were lower than IAPAR and both were similar to BN2. The IAPAR-REPASSE showed GEDC (70.62\%) and GEMC (68.49\%) similar to the Iapar. The Iapar- $1 \mathrm{~mm}(84.61$ and $81.41 \%)$ showed higher GEDC and GEMC than Iapar-3 mm (70.59 e 68.71\%) and Iapar-2 mm (77.73 e 75.46\%). The values of digestible energy (DE) and metabolizable energy (ME) for the Iapar (3 mm) were 3,030 kcal/ $\mathrm{kg}$ and 3,001 kcal/kg, respectively. The IAPAR (2 and $1 \mathrm{~mm})$ showed DE of 3,083 and 3,355kcal/ $\mathrm{kg}$ and ME of 2,993 and 3,228 kcal/kg. The Iapar-Repasse showed the values of: 2,849 kcal/kg (DE) and 2,763 kcal/kg (ME). The COMUM ( 3 and $2 \mathrm{~mm}$ ) showed values of: 2,574 and 3,022 kcal/kg (DE) and 2,497 and 2,932 kcal/kg (ME). The BN2 (3 and $2 \mathrm{~mm}$ ) showed values of: 2,692 and 3,047 kcal/kg (DE); 2,620 and 2,966 kcal/kg (ME). The different pearl millets showed variations in chemical composition. The differences result in variations on nutritional values. The Iapar pearl millet, showed the best values, followed by BN2 and Comum.
\end{abstract}

Key Words: alternative feeds, digestible nutrients, granulometry

\section{Introduçãa}

O crescimento da cultura do milheto no Brasil, sobretudo na região Centro-Oeste, propiciou a disponibilização do grão de milheto no mercado brasileiro, viabilizando sua utilização na alimentação animal, uma vez que possui bom valor nutricional, principalmente para animais monogástricos (Bandeira et al., 1996; Nunes et al., 1997; Pádua et al., 1997).

Bastos et al. (2002), testando níveis de inclusão de até $60 \%$ de milheto em rações de suínos, constataram que não houve redução no desempenho ou qualquer alteração nas características de carcaça.

O grão de milheto possui bom valor nutricional na alimentação animal, pois apresenta teor de proteína

\footnotetext{
${ }^{1}$ Parte da Tese de doutorado do primeiro autor, apresentada á Universidade Estadual de Maringá (UEM), parcialmente financiada pela Fundação ARAUCÁRIA do Paraná.

2 Doutor em Zootecnia do Ministério da Agricultura, Pecuária e do Abastecimento - DFA/Paraná.

3 Professor do Departamento de Zootecnia da UEM. E.mail: imoreira@uem.br (Av. Colombo, 5790. CEP:87020-900 Maringá-PR).

${ }^{4}$ Alunos do curso de Doutorado da UNESP-SP.

${ }^{5}$ Pesquisador do Instituto Agronômico do Paraná - IAPAR.

* Autor para correspondência.
} 
superior ao milho, variando de 12 a 14\% (Walker, 1987). O teor de aminoácidos do milheto é superior ao do sorgo e do milho e comparável ao de outros pequenos grãos, como a cevada e o arroz (Ejeta et al., 1987). O teor de lisina na proteína varia de 1,9 a 3,9 g/ 100g (Ejeta et al., 1987, Hoseney et al. 1987).

Segundo Adeola \& Orban (1995), o milheto possui maior quantidade de lisina, principal aminoácido limitante na criação de suínos. A metionina e treonina, segundo e o terceiro aminoácidos limitantes, também são mais elevados no milheto que no milho.

O teor de extrato etéreo do milheto, segundo Lawrence et al. (1995), é duas vezes maior que do milho, o que poderia explicar a maior energia bruta para o milheto em relação ao milho. Adeola \& Orban (1995) obtiveram, para o milho, energia bruta de $3.788 \mathrm{kcal} / \mathrm{kg}$ e de $4.132 \mathrm{e} 4.307 \mathrm{kcal} / \mathrm{kg}$, para as duas variedades de milheto.

A composição química dos milhetos apresenta grande variação. O teor de proteína bruta, por exemplo, oscilou de 8,8 a 20,9\% em 180 amostras testadas (Burton et al., 1972). Segundo Andrews \& Kumar (1992), estas diferenças seriam decorrentes das variações no manejo, nas condições climáticas e nas diferenças entre variedades.

O valor energético é o principal limitante na inclusão de milheto em rações de suínos, pois, embora a energia bruta do milheto seja superior à do milho, a concentração de energia digestível para suínos é cerca de $15 \%$ inferior (Viana, 1982). Lawrence et al. (1995) obtiveram valores de 3.170 e $2.900 \mathrm{kcal}$ de energia digestível/kg, para o milho e milheto, respectivamente, atribuídos à maior quantidade de fibra em detergente neutro e fibra em detergente ácido do milheto, o que pode provocar diminuição no aproveitamento da energia bruta.

No Brasil, Fialho et al. (1999) obtiveram valores de $3.080 \mathrm{kcal}$ de ED/kg e $2.930 \mathrm{kcal}$ de EM/kg do milheto.

Adeola \& Orban (1995), analisando duas variedades de milheto, obtiveram valores de 3.107 e $3.292 \mathrm{kcal}$ de ED/kg de matéria seca, que foram superiores ao milho testado, cujo valor foi de $3.110 \mathrm{kcal} / \mathrm{kg}$. Ressalta-se que os grãos foram moídos em peneira de $1 \mathrm{~mm}$, diferente dos padrões adotados em condições comerciais, o que poderia explicar a melhora no valor de ED.

Em virtude do pequeno tamanho do grão de milheto, sua moagem em peneira de $3 \mathrm{~mm}$, normalmente utilizada, resulta na presença de razoável quantidade de grãos praticamente intactos, o que diminui sua utilização metabólica pelos suínos, pois a presença da casca reduz a ação das enzimas digestivas (Dove \& Myer, 1995).

Objetivou-se neste trabalho estudar, em suínos, a composição química, a digestibilidade dos nutrientes e da energia de diferentes milhetos, processados em moinhos com peneiras de diferentes diâmetros de furo.

\section{Material e Métodos}

Foram conduzidos dois ensaios de digestibilidade para avaliar três diferentes milhetos (o cultivar COMUM, a variedade BN2 e a linhagem IAPAR-IA98301) processados em moinhos com peneiras com três diferentes diâmetros de furo. Os dois primeiros milhetos foram escolhidos por serem os dois mais difundidos e utilizados no Brasil, enquanto o último representa uma nova linhagem que, em breve, estará disponível no mecado.

Os ensaios de digestibilidade foram conduzidos na Sala de Metabolismo de Suínos da Fazenda Experimental de Iguatemi da Universidade Estadual de Maringá.

No Ensaio 1, foram determinados os valores de digestibilidade de quatro diferentes milhetos (BN2, IAPAR e IAPAR-REPASSE - Resíduo do processo de seleção de sementes, formados por grãos miúdos chochos ou quebradiços, e o COMUM). Os três primeiros foram triturados em moinho com peneira de 3,0 $\mathrm{mm}$ e o COMUM, também em moinho com peneira de 2,0 $\mathrm{mm}$. No Ensaio 2, determinou-se a digestibilidade do milheto $\mathrm{BN} 2$, processado em moinho com peneira de furo de 2,0 mm de diâmetro, e a linhagem IAPAR, com três diferentes graus de moagem (peneiras de 3,0, 2,0 e 1,0 mm), realizando-se, ainda, análise química do BN2 com a espigueta e do REPASSE.

No Ensaio 1, foram utilizados 12 suínos machos castrados, com peso médio inicial de 22,8 $\pm 0,9 \mathrm{~kg}$ e, no Ensaio 2, outros 12 suínos, com peso médio inicial de 24,3 $\pm 1,7 \mathrm{~kg}$. Os animais foram alojados individualmente em gaiolas de estudos metabólicos tipo "Pekas", onde foram registradas as temperaturas mínimas de $21,2 \pm 2,2^{\circ} \mathrm{Ce}$ $21,3 \pm 2,3^{\circ} \mathrm{C}$ e máximas de $27,4 \pm 2,1^{\circ} \mathrm{C}$ e $30,7 \pm 2,3^{\circ} \mathrm{C}$, no primeiro e segundo ensaios, respectivamente.

Cada ensaio foi constituído por dois períodos. O primeiro teve duração de 12 dias (sete dias para adaptação às gaiolas e às rações experimentais e cinco para coleta total de fezes e urina) e o segundo, de 10 dias (cinco de adaptação às rações e cinco de coleta). No segundo período, conduzido imediatamente 
após o primeiro, os animais foram redistribuídos entre os diferentes tratamentos.

A ração-referência, à base de milho e farelo de soja, foi formulada de acordo com a composição química e com os valores energéticos indicados por Rostagno et al. (1983), atendendo às exigências do NRC (1998) para suínos em crescimento $(25-50 \mathrm{~kg})$. As rações-teste continham $70 \%$ da ração-referência e $30 \%$ do alimento em teste na base da matéria natural.

Constam na Tabela 1 os teores de matéria seca, proteína bruta e energia bruta dos milhetos utilizados em cada período do ensaio de digestibilidade.

As rações foram oferecidas em duas refeições diárias, às 8 e 16 h, com a quantidade estabelecida, durante o perído de coleta, de acordo com o consumo médio durante o período de adaptação e o peso metabólico $\left(\mathrm{kg}^{0,75}\right)$ dos animais antes do início do período de coleta.

A água foi fornecida no comedouro após as refeições, na proporção de $3,0 \mathrm{~mL} / \mathrm{g}$ de ração consumida.

O método adotado foi o de coleta total de fezes, empregando-se $2 \%$ de óxido férrico para definir o

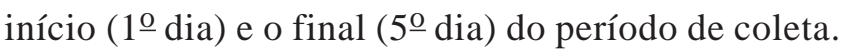

Os procedimentos de coleta e manipulação das fezes e da urina foram semelhantes aos descritos por Fialho et al. (1983) e Moreira et al. (1994).

Para determinação dos coeficientes de digestibilidade (CD), foram calculados os valores de matéria seca, proteína bruta e energia bruta das rações-teste, rações-referência e das fezes e a energia bruta da urina, de acordo com Silva (1990). Os coeficientes de digestibilidade da matéria seca (CDMS), proteína bruta (CDPB) e energia bruta
(CDEB) e o coeficiente de metabolização da energia bruta (CMEB) dos alimentos foram calculados utilizando a fórmula de Matterson et al. (1965).

Os CD foram submetidos à análise de variância dentro de cada período, por intermédio do pacote estatístico SAEG (UFV, 1997), e as diferenças entre as médias foram estimadas pelo teste de StudentNewman-Keuls (SNK), a 5\% de probabilidade.

\section{Resultados e Discussão}

Os resultados das análises de composição química e energética dos diferentes milhetos encontram-se na Tabela 2.

Os milhetos apresentaram teores de proteína bruta, em média, $47 \%$ superiores ao milho e a menor diferença observada foi com o milheto IAPARNormal, de 38,4\%. Adeola \& Orban (1995), analisando duas variedades de milheto, encontraram valores de proteína bruta superiores aos do milho em 33 e $48 \%$, resultados semelhantes aos observados por Burton et al. (1972).

A diminuição do tamanho do grão propicia aumento proporcional na quantidade do gérmen, em detrimento do endosperma e da casca. O gérmen possui maior quantidade de proteína (Kumar, 1999) e a palha, alta quantidade de proteína lignificada.

Para se conhecer a massa do grão (Tabela 3), foram pesados (g) 1.000 grãos de cada um dos milhetos.

O tamanho do grão não possui relação direta com seu valor de energia bruta, pois o milheto BN2, de menor tamanho, apresentou valor superior ao COMUM e ao pequeno BN2, que tem valores de

Tabela 1 - Teores de matéria seca, proteína bruta e energia bruta dos milhetos utilizados no Ensaio 1 e Ensaio 2 (valores na matéria natural)

Table 1 - Percentual dry matter, crude protein and gross energy values with pearl millets used in first and second digestibility trials (as fed basis)

\begin{tabular}{|c|c|c|c|c|c|c|}
\hline \multirow[t]{3}{*}{$\begin{array}{l}\text { Item } \\
\text { Item }\end{array}$} & & \multicolumn{5}{|c|}{$\begin{array}{c}\text { Milheto } \\
\text { Pearl millet }\end{array}$} \\
\hline & \multicolumn{4}{|c|}{$\begin{array}{l}\text { Primeiro ensaio } \\
\text { First trial }\end{array}$} & \multicolumn{2}{|c|}{$\begin{array}{l}\text { Segundo ensaio } \\
\text { Second trial }\end{array}$} \\
\hline & COMUM & IAPAR & REPASSE & BN2 & IAPAR & BN2 \\
\hline $\begin{array}{l}\text { Matéria seca, \% } \\
\text { Dry matter, \% }\end{array}$ & 89,44 & 90,61 & 89,13 & 87,31 & 86,73 & 89,52 \\
\hline $\begin{array}{l}\text { Proteína bruta, } \% \\
\text { Crude protein, } \%\end{array}$ & 13,83 & 11,63 & 11,47 & 12,61 & 11,81 & 14,91 \\
\hline $\begin{array}{l}\text { Energia bruta,\% } \\
\text { Gross energy }\end{array}$ & 4.073 & 4.042 & 4.034 & 3.986 & 3.967 & 4.018 \\
\hline
\end{tabular}


Tabela 2 - Composição química e energética do milho e dos milhetos (valores na matéria seca) Table 2 - Chemical and energy composition of corn and pearl millets (dry matter basis)

\begin{tabular}{|c|c|c|c|c|c|c|c|}
\hline \multirow[t]{3}{*}{$\begin{array}{l}\text { Nutriente } \\
\text { Nutrient }\end{array}$} & \multirow{3}{*}{$\begin{array}{l}\text { Milho }{ }^{1} \\
\text { Corn }^{1}\end{array}$} & \multicolumn{5}{|c|}{$\begin{array}{l}\text { Milheto } \\
\text { Pearl millet }\end{array}$} & \\
\hline & & \multirow[t]{2}{*}{ Comum } & \multicolumn{2}{|c|}{ BN2 } & \multicolumn{3}{|c|}{ IAPAR } \\
\hline & & & NORMAL & REPASSE & BN2S & NORMAL & REPASSE \\
\hline $\begin{array}{l}\text { Matéria seca, } \% \\
\text { Dry matter, } \%\end{array}$ & 87,10 & 90,46 & 87,31 & 89,52 & 88,93 & 86,73 & 89,13 \\
\hline $\begin{array}{l}\text { Proteína bruta, \% } \\
\text { Crude protein, \% }\end{array}$ & 9,84 & 15,34 & 14,44 & 16,66 & 17,66 & 13,62 & 12,86 \\
\hline $\begin{array}{l}\text { Energia bruta, } \mathrm{kcal} / \mathrm{kg} \\
\text { Gross energy, } \mathrm{kcal} / \mathrm{kg}\end{array}$ & 4.515 & 4.503 & 4.575 & 4.498 & 4.468 & 4.572 & 4.527 \\
\hline $\begin{array}{l}\text { Extrato etéreo, } \% \\
\text { Ether extract, } \%\end{array}$ & 3,97 & 4,71 & 4,29 & 3,23 & 3,07 & 4,23 & 4,52 \\
\hline $\begin{array}{l}\text { Fibra bruta, } \% \\
\text { Crude fiber, } \%\end{array}$ & 2,24 & 1,17 & 1,31 & 2,30 & 3,33 & 1,61 & 1,26 \\
\hline $\begin{array}{l}\mathrm{FDN}^{2}, \% \\
N D F^{2}, \%\end{array}$ & 13,09 & 20,58 & 13,98 & 22,69 & 27,63 & 12,12 & 18,99 \\
\hline $\begin{array}{l}\mathrm{FDA}^{3}, \% \\
A D F^{3}, \%\end{array}$ & 3,84 & 4,67 & 3,93 & 6,73 & 7,14 & 3,81 & 3,44 \\
\hline $\begin{array}{l}\text { Amido, } \% \\
\text { Starch, \% }\end{array}$ & 71,53 & 69,74 & 72,69 & 64,78 & 61,98 & 76,36 & 70,60 \\
\hline $\begin{array}{l}\text { Cinzas, } \% \\
\text { Ash, \% }\end{array}$ & 1,47 & 1,47 & 1,93 & 1,95 & 2,06 & 1,79 & 1,63 \\
\hline $\begin{array}{l}\text { Cálcio, \% } \\
\text { Calcium, \% }\end{array}$ & 0,03 & 0,06 & 0,06 & 0,06 & 0,08 & 0,06 & 0,06 \\
\hline $\begin{array}{l}\text { Fósforo, \% } \\
\text { Phosphorus, \% }\end{array}$ & 0,28 & 0,28 & 0,36 & 0,32 & 0,34 & 0,33 & 0,30 \\
\hline
\end{tabular}

1 Valores baseados em Rostagno et al. (2000).

${ }^{2}$ Fibra em detergente neutro.

${ }^{3}$ Fibra em detergente ácido.

1 Values from Rostagno et al. (2000).

2 Neutral detergent fiber.

${ }^{3}$ Acid detergent fiber.

energia bruta maiores que o IAPAR. Kumar (1999) cita como um dos objetivos do melhoramento o aumento do tamanho do grão, pois estaria relacionado ao teor de energia do milheto, em função do aumento da proporção endosperma/pericarpo, mas este comportamento não foi observado neste estudo.

O teor de extrato etéreo dos milhetos foi superior ao do milho, corroborando os resultados reportados por Sulivan et al. (1990) e Adeola \& Orban (1995). Adeola \& Orban (1995), por exemplo, obtiveram, em duas variedades de milhetos, valores superiores a $300 \%$ em relação ao milho. Entretanto, neste estudo, a diferença média foi de apenas $11 \%$, fato que talvez possa explicar as proximidades entre os valores de energia bruta dos milhetos e do milho.

O teor de amido do milheto COMUM é inferior ao do milho. Por outro lado, o do BN2 e do IAPAR são
Tabela 3 - Massa do grão de diferentes milhetos Table 3 - Mass of grain of different types of pearl millets

\begin{tabular}{lc}
\hline Milheto & Peso (g/1.000 grãos) \\
Pearlmillet & Weight $($ g/l,000 grains $)$ \\
\hline BN2 & 6,0 \\
COMUM & 9,8 \\
IAPAR & 17,8 \\
\hline
\end{tabular}

superiores. Em uma comparação entre os milhetos, o tamanho do grão não foi determinante da concentração de amido. Os valores de amido obtidos com os diferentes milhetos (Tabela 2 ) foram um pouco elevados, quando comparados à faixa de variação descrita por Stringhni et al. (1999), de 57,4 a 70,3\%.

A composição aminoacídica dos milhetos encontra-se na Tabela 4. As concentrações de lisina dos 
milhetos foram similares aos valores reportados por Burton et al. (1972), que analisaram 23 amostras de milheto e todas estiveram na faixa de 0,31 a $0,54 \%$ na matéria natural do grão.

Os teores de metionina e treonina foram mais elevados nas três variedades de milheto, quando comparadas com o milho (Tabela 4). Para triptofano, a literatura reporta, também, maior teor deste aminoácido para o milheto (NRC, 1998; Rostagno et al., 2000).

Os resultados, quando comparados aos dados da literatura brasileira (Rostagno et al. 2000), indicaram que o milheto BN2 apresenta valores de composição química bastante próximos.

Seria esperado que os perfis da proteína dos milhetos fossem os mesmos, mas, ao comparar o percentual de cada aminoácido na proteína, verificase que estes perfis não são mantidos, observando-se, por exemplo, diferença de $14 \%$ no teor de lisina entre o BN2 e o IAPAR, ou, ainda, de quase $31 \%$ no teor de metionina+cistina.

NaTabela5, constam os coeficientes de digestibilidade aparente do Ensaio 1. Não foram observadas diferenças $(\mathrm{P}>0,05)$ entre os CDMS, entre as três variedades de milheto ou entre as diferentes granulometrias. Porém, a redução da granulometria propiciou aumentonumérico do CDMS para o milheto COMUM.

Os CDPB, para as duas granulometrias testadas e para o IAPAR-REPASSE, não foram diferentes $(\mathrm{P}>0,05)$, ao passo que o $\mathrm{BN} 2$ apresentou menor $(\mathrm{P}<0,05)$ CDPB que os outros milhetos, exceção feita ao COMUM-3 mm, que apresentou valor semelhante.

Os CDEB e CMEB apresentaram o mesmo comportamento, ou seja, foram influenciados pela granulometria. O milheto COMUM-3 $\mathrm{mm}$ teve o CDEB e CMEB semelhantes ao BN2, enquanto a linhagem IAPAR apresentou valores superiores ao milheto COMUM.

Os coeficientes de digestibilidade aparente do Ensaio 2, estão apresentados na Tabela 6. Não foram observadas diferenças $(\mathrm{P}>0,05)$ entre os CDMS entre os dois milhetos ou entre as diferentes granulometrias. A granulometria, entretanto, influenciou os CDPB, CDEB e CMEB. O milheto IAPAR-3 mm apresentou menor CDPB que o IAPAR-2 mm e IAPAR-1 mm. Para os CDEB e CMEB o IAPAR-3 mm e o IAPAR $2 \mathrm{~mm}$ apresentaram valores inferiores ao IAPAR-1 mm.

Verificou-se maior CDPB para o milheto BN2-2 mm que para o IAPAR-3 mm e CDEB e CMEB inferior ao IAPAR-1 mm, indicando que, apesar do maior tamanho, o BN2-2 ainda não é grande o suficiente para uma moagem adequada em peneira de $2 \mathrm{~mm}$.

O grau de moagem possui grande importância para os coeficientes de digestibilidade. Para o CDPB, parece que a redução do tamanho da peneira de $3 \mathrm{~mm}$ para $2 \mathrm{~mm}$ foi o suficiente para o bom aproveitamento da proteína ingerida, entretanto, o CDEB e CMEB foram maximizados quando o alimento foi moído em peneira de $1 \mathrm{~mm}$.

Os CDMS do milheto IAPAR e BN2 foram próximos aos reportados por Lawrence et al. (1995), que encontraram valores de 75,5 e 78,8\% para duas variedades de milheto. Entretanto, o milheto COMUM apresentou (Tabela 5) valor bem inferior $(63,07 \%)$ quando moído em peneira tradicional ( $3 \mathrm{~mm})$, o que foi melhorado com moagem mais fina $(2 \mathrm{~mm})$.

O tamanho do grão, portanto, foi um dos responsáveis por este menor valor, pois, graças ao pequeno tamanho, o grão não foi adequadamente moído em peneira tradicional, possibilitando a presença de grãos inteiros após a moagem, o que pôde ser observado visualmente nas fezes dos animais alimentados com a ração contendo o milheto moído em peneira tradicional de $3 \mathrm{~mm}$.

O processamento em moinho com peneira de 1 mm propiciou melhor valor do CDMS $(85,16 \%)$ que os valores $(80,85$ e $82,03 \%$ para dois milhetos) apresentados por Adeola \& Orban (1995), que utilizaram moinho com peneira de mesmo diâmetro.

Os CDPB e CDEB do IAPAR-1 $\mathrm{mm}$ foram próximos aos registrados (84,4 e 84,8\%) por Haydon $\&$ Hobbs (1991) e inferiores aos relatados por Fialho et al. (1999), para o CDPB $(86,20 \%)$.

Na Tabela 7, estão compilados os dados do Ensaio 1 e do Ensaio 2, para matéria seca digestível (MSD), proteína digestível (PD), energia digestível (ED) e energia metabolizável (EM) dos diferentes milhetos.

As diferenças observadas na ED, EM, PD e MSD foram similares às citadas na literatura (Haydon \& Hobbs, 1991; Adeola \& Orban, 1995; Lawrence et al., 1995; Fialho et al., 1999), evidenciando as grandes variações nos valores nutricionais dos diferentes milhetos analisados. Contudo, a não-identificação das variedades dos milhetos estudados nestes trabalhos dificulta a comparação destas diferenças.

Observou-se (Tabela 7) que a redução do tamanho dos furos da peneira de três para dois milímetros, na moagem do milheto, promoveu aumento no teor de MSD e PD, à exceção do BN2, para o MSD. Entre- 
Tabela 4 - Composição aminoacídica e perfil de aminoácidos da proteína bruta dos milhetos e do milho (valores na matéria seca)

Table 4 - Amino acid composition and amino acid profile of crude protein of pearl millets and corn (values as dry matter)

Aminoácido, \%

Milheto

Amino acid, \%

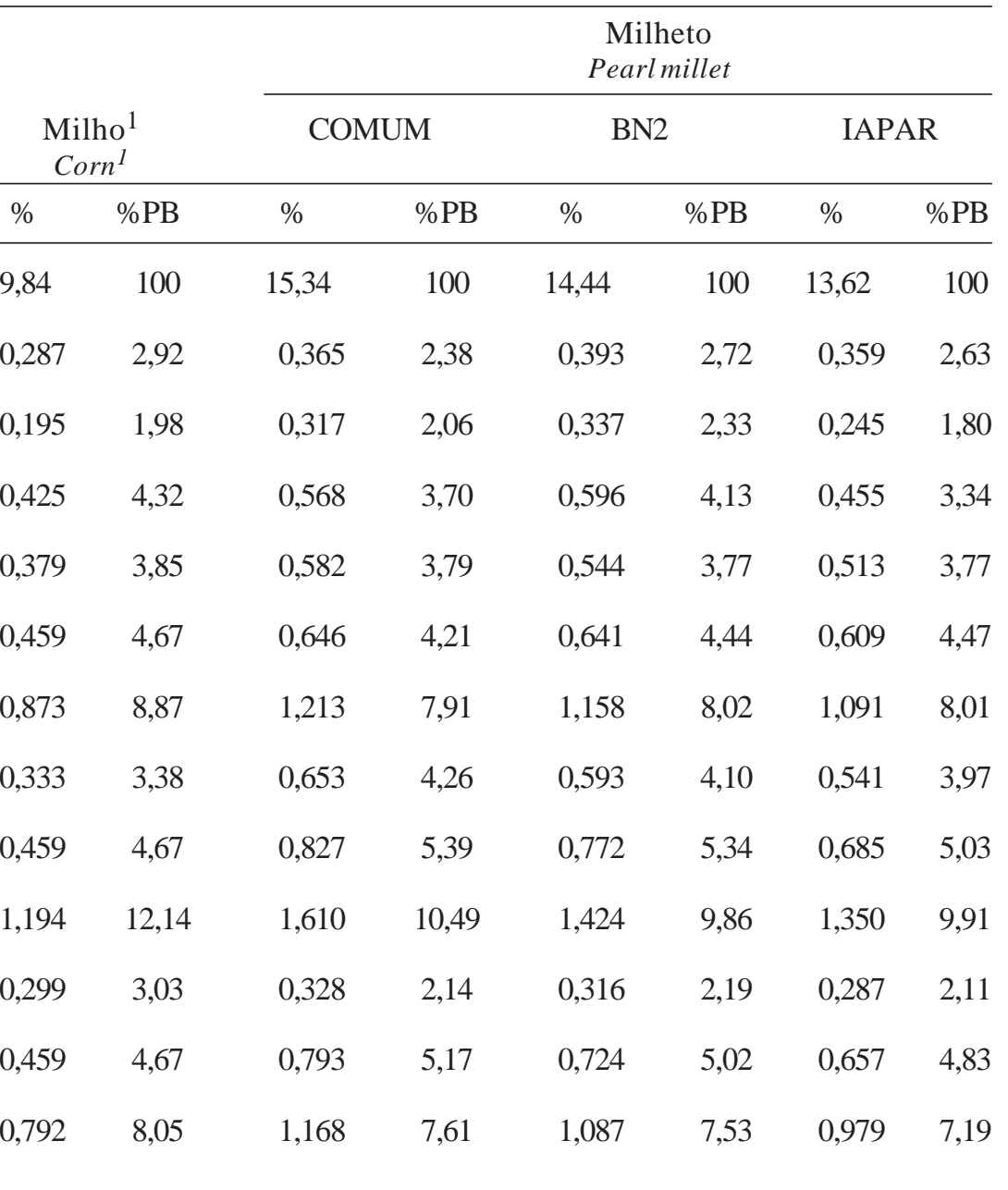

${ }^{1}$ Valores baseados em Rostagno et al. (2000).

1 Values from Rostagno et al. (2000).

tanto, esta resposta não ocorreu quando da redução para $1 \mathrm{~mm}$. Os valores de ED e EM não apresentaram o mesmo comportamento, pois a melhora também ocorreu quando desta redução, indicando que o melhor aproveitamento da energia ocorre apenas com uma moagem mais fina.Esta melhora não deve ser associada apenas ao maior valor de digestibilidade, que ocorre naturalmente com a diminuição da partícula de um ingrediente qualquer, em função do aumento do tempo de retenção do alimento no trato gastrintestinal do animal. A melhoria observada foi bastante acentuada em comparação ao milho. Por exemplo, a utilização de peneiras de 0,45 e $0,25 \mathrm{~mm}$ promoveu, segundo Zanotto et al. (1995), melhores teores de PD e ED, em torno de $2 \%$, mesmo promovendo redução no tamanho da partícula ainda maior que a utilizada neste ensaio.
A grande diferença observada deve estar relacionada às pequenas dimensões do grão de milheto, o que proporciona inadequada moagem, com a passagem de grãos inteiros, que são praticamente indigestíveis, uma vez que a camada externa torna-se uma barreira, reduzindo a ação das enzimas digestivas sobre o endosperma.

Comparando-se os valores de ED e EM dos três milhetos testados, quando processados em moinho com peneira de dois milímetros, observou-se menor variação nos valores nutricionais, sugerindo que, apesar da diferença na composição química dos milhetos, as variações observadas na literatura poderiam estar, em grande parte, relacionadas a uma variação no grau de fracionamento dos grãos após a moagem.

O milheto IAPAR-REPASSE apresentou digestibilidade inferior ao IAPAR, porém com valores 


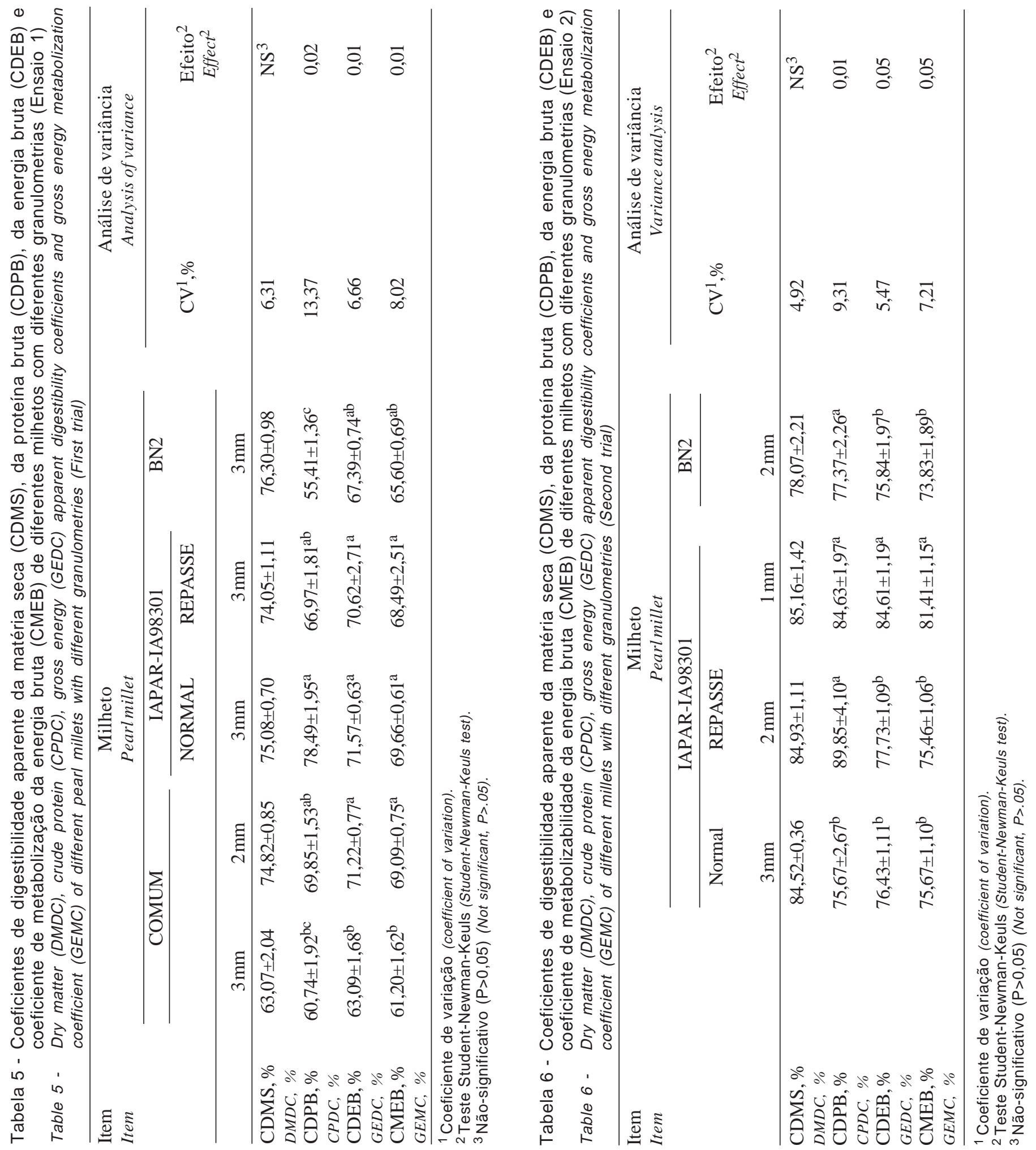


Tabela 7 - Valores de matéria seca digestível (MSD), proteína digestível (PD), energia digestível (ED) e energia metabolizável (EM) de diferentes milhetos com diferentes granulometrias (valores na matéria natural) ${ }^{1}$

Table 7 - Values of digestible dry matter(DDM), digestible protein (DP), digestible energy (DE) and metabolizable energy (ME) of different pearl millets with different granulometries (Values as fed basis) ${ }^{1}$

\begin{tabular}{|c|c|c|c|c|c|c|c|c|}
\hline \multirow[t]{3}{*}{$\begin{array}{l}\text { Nutriente } \\
\text { Nutrient }\end{array}$} & \multicolumn{8}{|c|}{$\begin{array}{c}\text { Milheto } \\
\text { Pearl millet }\end{array}$} \\
\hline & \multicolumn{3}{|c|}{ IAPAR-IA98301 } & \multirow{2}{*}{$\frac{\text { REPASSE }}{3 \mathrm{~mm}}$} & \multicolumn{2}{|c|}{ COMUM } & \multicolumn{2}{|c|}{$\mathrm{BN} 2$} \\
\hline & $3 \mathrm{~mm}$ & $2 \mathrm{~mm}$ & $1 \mathrm{~mm}$ & & $3 \mathrm{~mm}$ & $2 \mathrm{~mm}$ & $3 \mathrm{~mm}$ & $2 \mathrm{~mm}$ \\
\hline $\begin{array}{l}\text { MSD, \% } \\
D D M \%\end{array}$ & 66,99 & 73,66 & 73,86 & 74,05 & 62,26 & 74,82 & 72,02 & 69,89 \\
\hline $\begin{array}{l}\mathrm{PD}, \% \\
D P, \%\end{array}$ & 7,24 & 10,61 & 10,00 & 7,68 & 8,44 & 9,69 & 6,99 & 11,54 \\
\hline $\begin{array}{l}\mathrm{ED}, \mathrm{kcal} / \mathrm{kg} \\
D E, k c a l / k g\end{array}$ & 3.030 & 3.083 & 3.355 & 2.849 & 2.574 & 3.022 & 2.692 & 3.047 \\
\hline $\begin{array}{l}\mathrm{EM}, \mathrm{kcal} / \mathrm{kg} \\
M E, \mathrm{kcal} / \mathrm{kg}\end{array}$ & 3.001 & 2.993 & 3.228 & 2.763 & 2.497 & 2.932 & 2.620 & 2.966 \\
\hline
\end{tabular}

1 Valores compilados dos ensaios 1 e 2 .

${ }^{1}$ Values compilated with first and second trials.

de ED superiores às duas outras variedades de milheto. Também a PD foi superior à de BN2, mas inferior à do cultivar COMUM.

É importante ressaltar que a utilização do resíduo da produção de sementes, ou do BN2 com espigueta, torna mais difícil a formulação de ração, pois o resíduo apresenta maiores variações na composição química, em função das diferenças entre os lotes. Portanto, a utilização destes milhetos deve ser mais criteriosa, exigindo maiores cuidados no momento da formulação de rações para suínos.

\section{Conclusões}

Os diferentes tipos de milhetos apresentam variações em sua composição química, que resultam em diferenças no valor nutricional. Entre as variedades testadas, o milheto IAPAR é o que apresenta melhor valor nutricional, seguido pelo BN2 e COMUM.

A redução da granulometria melhora a digestibilidade da energia bruta e permite diminuição na variação do valor nutricional dos milhetos.

\section{Agradecimento}

À FUNDAÇÃO ARAUCÁRIA, ao INSTITUTO AGRONÔMICO DO PARANÁ (IAPAR) e às Sementes BONAMIGO, pela colaboração na condução da pesquisa.

\section{Literatura Citada}

ADEOLA, O.; ORBAN, J.I. Chemical composition and nutrient digestibility of pearl millet (Pennisetum glaucum) fed to growing pigs. Journal of Cereal Science, v.22, p.177-184, 1995.

ANDREWS, D.J.; KUMAR, K.A. Pearl millet for, food, feed and forage, Advances in Agronomy, v.48, p.89-139, 1992.

BANDEIRA, M.N.; NUNES, R.C.; FRANÇA, A.F.S. et al. Utilização do milheto grão como substituto do milho em rações para suínos na fase de terminação. Arquivos das Escolas de Agronomia e Veterinária da Universidade Federal de Goiás, v.26, n.2, p.57-64, 1996.

BASTOS, A.O.; LANDELL FILHO, L.C.; PASSIPIERI, M. et al. Diferentes níveis de grão de milheto (Pennisetum glaucum $(\mathrm{L}$. R. Brown) na alimentação de suínos. Revista Brasileira de Zootecnia, v.31, n.4, p.1753-1760, 2002.

BURTON, G.W.; WALLACE, A.T.; RACHIE, K.O. Chemical composition and nutritive value of pearl millet (Pennisetum typhoyde) grain. Crop Science, v.12, p.187, 1972.

DOVE, C.R.; MYER, R.O. Swine performance on HGM pearl millet grain. 100. In: NATIONAL GRAIN PEARL MILLET SYMPOSIUM, 1., 1995, Georgia. Proccedings... Georgia: University of Georgia, 1995. p.110-113.

EJETA, G.; HANSEN, M.M.; MERTZ, E.T. In vitro digestibility and amino acid composition of pearl millet (Pennisetum typhoides) and others cereals. Proceedings of National Academy of USA, v.84, p.6016-6019, 1987.

FIALHO, E.T.; LIMA, J.A.F.; FRANGILO, R.S. et al. Uso de ensaios de metabolismo para determinação dos valores nutricionais de alguns alimentos com suínos. In: REUNIÃO ANUAL DA SOCIEDADE BRASILEIRA DEZOOTECNIA, 36., 1999, Porto Alegre. Anais... São Paulo: Sociedade Brasileira de Zootecnia/Gmosis, (1999), CD-ROM. Nutrição animal. Nutrição de Não Ruminantes. NUN115. 
FIALHO, E.T.; GOMES, P.C.; ALBINO L.F.T. et al. Determinação dos valores de composição química e de digestibilidade de alguns ingredientes nacionais para suínos. Revista Sociedade da Brasileira Zootecnia, v.12, n.2, p337-56, 1983.

HAYDON, K.D.; HOBBS, S.E. Nutrient digestibilities of soft winter, improved triticale cultivars and pearl millet for finishing pigs. Journal of Animal Science, v.69, p.719-725, 1991.

HOSENEY, R.C.; ANDREWS, D.J.; CLARK, H. Sorghum and pearl millet. In: NUTRICIONAL QUALITY OF CEREAL GRAINS: Genetic and Agronomic Improvement. Madison: American Society of Animal Science, 1987. p.397-456 (Monograph, 28).

KUMAR, A.O. milheto como cultura granífera para ração. In: WORKSHOP INTERNACIONAL DE MILHETO, 1, 1999. Brasília. Anais... Brasília: Empresa Brasileira de Pesquisa Agropecuária (EMBRAPA/Planaltina), 1999. p.113-130.

LAWRENCE, B.V.; ADEOLA, O.; ROGLER, J.C. Nutrient digestibility and growth performance of pigs fed pearl millet as a replacement for corn. Journal of Animal Science, v.73, n.7, p.2026-2032, 1995.

MATTERSON, L.D.; POTTER, L.M.; STUTZ, M.W. et al. The metabolizable energy of feed ingredients for chickens. Research Report, v.7, n.1, p.11-14, 1965.

MOREIRA, I.; ROSTAGNO, H.S.; SILVA, M.A.; TAFURY, M.L. Determinação dos coeficientes de digestibilidade, valores energéticos e índices de controle de qualidade do milho e soja integral processados a calor. Revista da Sociedade Brasileira de Zootecnia, v.23, n.6, p.916-929, 1994.

NATIONAL RESEARCH COUCNIL - NRC. Nutrients requirements of swine. 10.ed. Washington. D.C.: National Academic Press, 1998. 189p.

NUNES, R.C.; BANDEIRA, M.N.; FRANÇA, A.F.S. et al. Utilização do milheto grão como substituto do milho em rações para suínos na fase de crescimento. Arquivos das Escolas de Agronomia e Veterinária da Universidade Federal de Goiás, v.27, n.2, p.41-48, 1997.

PÁDUA, D.M.C.; SILVA, P.C.; FRANÇA, A.F.S. et al. Produção e rendimento de carcaça da tilápia Nilótica Oreochromis niloticus, alimentada com dietas contendo farelo de milheto. In: REUNIÃO ANUAL DA SOCIEDADE BRASILEIRA DE ZOOTECNIA, 35., 1999, Porto Alegre. Anais... Porto Alegre: Sociedade Brasileira de Zootecnia, 1999. p.314.
ROSTAGNO, H.S.; ALBINO, L.F.T.; DONZELE, J.L. et al.. Tabelas brasileiras para aves e suínos - Composição de alimentos e exigências nutricionais. Viçosa, MG: Universidade Federal de Viçosa, 2000. 141p.

ROSTAGNO, H.S.; SILVA, D.J.; COSTA, P.M.A et al. Composição de alimentos e exigências nutricionais de aves e suínos.Tabelas Brasileiras Viçosa, MG: Universidade Federal de Viçosa, 1983. 59p.

SILVA, D.J. Análise de alimentos (métodos químicos e biológicos). 2.ed. Viçosa, MG: Universidade Federal de Viçosa, 1990. 165 p.

STRINGHINI, J.H.; ORSINE, G.F.; FRANÇA, A.F.S. et al. Utilização do milheto como substituto do milho em rações para suínos em terminação, In: CONGRESSO BRASILEIRO DE MEDICINA VETERINÁRIA, 22., 1992, Curitiba. Anais... Curitiba: Sociedade Paranaense de Medicina Veterinária, 1992. Resumo 421.

SULIVAN, T.W.; DOUGLAS, J.H.; ANDREWS, D.J. et al. Nutrition value of pearl millet for food and feed. In: INTERNATIONAL CONFERENCE ON SORGHUN NUTRITIONAL QUALITY, 1990, Indiana. Proceedings... Indiana: Purdue University, 1990. p.83-94.

UNIVERSIDADE FEDERAL DE VIÇOSA - UFV. SAEG Sistemas de análises estatísticas e genéticas. Versão 7.1. Viçosa, MG: 1997. 150p. (Manual do usuário)

VIANA, S.P. Utilização de milheto em rações para aves e suínos como alternativa energética para algumas regiões do semiárido. In: Cultura do milheto. Fortaleza: Empresa Pernambucana de Pesquisa Agropecuária, 1982. p.59-63. (Monografias, 8)

WALKER, C.E. Evaluating pearl millet for food quality. In: INTSORMIL Annual Report. Lincoln: University of Nebraska- p.160-166, 1987.

ZANOTTO, L.D.; NICOLAIEWSKY, S.; FERREIRA, A.S. et al. Granulometria do milho na digestibilidade das dietas para suínos em crescimento e terminação. Revista da Sociedade Brasileira de Zootecnia, v.24, n.3, p.428-436, 1995.

Recebido em: 25/10/03 Aceito em: 23/01/05 